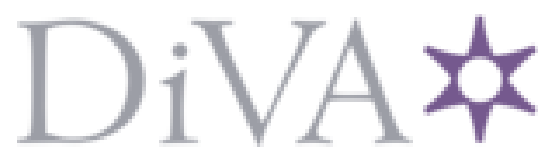

http://www.diva-portal.org

\title{
Postprint
}

This is the accepted version of a paper published in Phronesis: A Journal for Ancient Philosophy. This paper has been peer-reviewed but does not include the final publisher proof-corrections or journal pagination.

Citation for the original published paper (version of record):

Grönroos, G. (2015)

Wish, Motivation and the Human Good in Aristotle.

Phronesis: A Journal for Ancient Philosophy, 60(1): 60-87

http://dx.doi.org/10.1163/15685284-12341279

Access to the published version may require subscription.

N.B. When citing this work, cite the original published paper.

Permanent link to this version:

http://urn.kb.se/resolve?urn=urn:nbn:se:su:diva-113109 


\title{
Wish, Motivation, and the Human Good in Aristotle
}

In Phronesis 60 (2015) 60-87

\section{Gösta Grönroos}

Department of Philosophy, Stockholm University

SE - 10691 Stockholm, Sweden. Sweden

goesta.groenroos@philosophy.su.se

\begin{abstract}
Aristotle's invokes a specifically human desire, namely wish (boulēsis), to provide a teleological explanation of the pursuit of the specifically human good in terms of virtuous activity. Wish is a basic, unreasoned desire which, independently of other desires, or evaluative attitudes, motivates the pursuit of the human good. Even a person, who pursues what she mistakenly believes to be good, is motivated by wish for what in fact is good, although she is oblivious of it.
\end{abstract}

\section{Keywords}

Aristotle; wish; motivation; teleology; human good; representation

\section{Introduction}

A striking feature of Aristotle's psychology is the assumption of a specifically human desire,

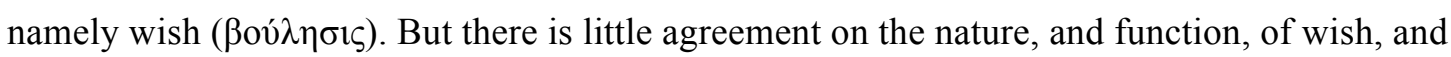
even on its most basic characteristics. For instance, despite fairly straightforward evidence for the view that wish is located in the rational part of the soul (DA 3.9, 432b5-6; Top. 4.5, 126a13), there is significant dissent. ${ }^{1}$ Moreover, no one questions that wish is a desire for the good ( $\tau \dot{\alpha} \gamma \alpha \theta$ óv), but what notion of the good Aristotle has in mind is contested. ${ }^{2}$ These disagreements are no wonder, since Aristotle is not particularly explicit about wish, and the evidence is scattered in the corpus. Therefore, with some important exceptions, wish is treated on the sidelines of discussions of Aristotle's psychology, philosophy of action, and ethics. ${ }^{3}$

My approach does not differ significantly insofar as I too take my lead from the overall characteristics of Aristotle's psychology, philosophy of action and ethics. But I shall frame my exploration somewhat differently by posing the question why Aristotle invokes wish as a specifically human desire in the first place. In particular, what explanatory force does wish add 
to the desires of the non-rational part of the soul shared with non-rational animals, that is, appetite $\left(\dot{\varepsilon} \pi \imath v \mu \mu^{\prime} \alpha\right)$ and spirited desire $(\theta 0 \mu o ́ s)$ ?

I shall argue that wish is invoked in order to provide a teleological explanation of the pursuit of the specifically human end, which fulfils human nature. ${ }^{4}$ The idea is that wish is a basic desire which, independently of other desires, or evaluative attitudes, motivates pursuit of what is good for human beings specifically. Wish is, by nature ( human beings ( $E E$ 2.10, 1227a28-9). The human good, again, is virtuous activity, which manifests human rational nature, and which is an independent value in the sense that it is not reducible to, or derivable from, objects of other kinds of desire.

Although located in the rational part of the soul, wish motivates not only the exercises of the two intellectual virtues, namely theoretical understanding (бофía) and practical wisdom ( $\varphi \rho o ́ v \eta \sigma \iota \varsigma)$, but also exercises of character virtues. Wish motivates exercises of character virtue, such as just and courageous activity, since even these exercises are constitutive of the human

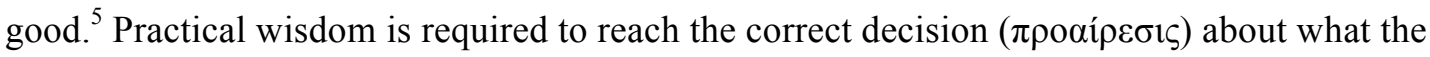
good thing to do is (NE 6.2, 1139a31-5; $N E$ 6.13, 1144a2-6). In the first place, practical wisdom is required to turn the natural ( 21). Full virtues, in turn, are dependent on the deliberative powers of practical wisdom in order to figure out what the good thing to do is. But the role of the rational part of the soul is not confined to providing the reasoning powers needed for exercising character virtues. For as I shall argue, the ultimate motivation to pursue exercises of character virtue is the rational part's desire for the human good.

The suggested interpretation seeks to make justice of the striking feature that reason, or

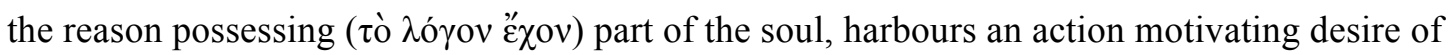
its own, but without succumbing to the intellectualist view that reason's own desire is the product of an exercise of reasoning. ${ }^{6}$ The intellectualist view goes against the Humean principle that the basic desires, which ultimately motivate actions, are unreasoned. ${ }^{7}$ But, as I shall argue, there are strong exegetic, and philosophical, objections to attributing this intellectualist view to Aristotle.

Against the view that wish is a basic desire for the specifically human good in terms of virtuous activity speaks the fact that Aristotle occasionally points out that wish is a desire for whatever people take to be good (NE 5.9, 1136b7-8; Rhet. 1.10, 1369a2-3). But I argue that Aristotle distinguishes between the representation of the good in terms of an action-guiding conception of the good on the one hand, and the source of motivation in terms of a basic desire on the other. For pursuit of the good, just as the pursuit of pleasure, is dependent on a representation of its object. But what a person represents as good, by the object's appearing 
good to her, may or may not be what really is good for her. On this point, I will suggest a Socratic reading of Aristotle, according to which people may pursue what they believe they desire, although it is not what they desire. So in a certain sense, a person may be oblivious of the fact that what she wishes for is not what she mistakenly believes to be good for her.

A further challenge to the suggestion that wish is invoked to provide a teleological explanation of the pursuit of the human good is the fact that so few people achieve this end, and that so few people even pursue what really is good for them in the first place. But if wish is invoked as part of a teleological explanation of human pursuit, and the end of that pursuit is the human good, then we may expect more success. Drawing on a few remarks in $E E 1.5$ on the conditions for figuring out what the good life consists in, and on an analogy in De Caelo 2.12, I argue that the specifically human good is particularly demanding to achieve, which explains both why people tend to fail in their pursuits, and why reasoning is such an important tool in forming a successful action-guiding conception of the human good. Nevertheless, what motivates such pursuit is a basic, and unreasoned, desire of the reason possessing part of the soul, namely wish.

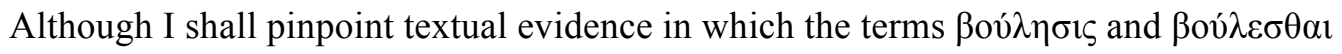
are, to my mind, used in the sense of a basic desire for the specifically human good, I do not claim a consistent use of these terms on Aristotle's part. Sometimes they just mean wishing or wanting in an unspecified and everyday sense. But picking out those instances that fit my interpretation may seem methodologically suspect. However, my argument is not primarily concerned with a particular terminology, but with a concept, with a particular theoretical purpose. In fact, I shall also use textual evidence in which these key terms are not employed, but which nevertheless testify to this concept.

\section{Reasoning based and pleasure based accounts of wish}

Before I turn to the evidence for the view that wish is a basic, unreasoned desire for the human good, I briefly discuss the main alternatives. A crucial point in the scholarly debate concerns the question whether wish is a reasoned desire. The two theses, that wish is for the end ( $N E$ 3.2, $1111 \mathrm{~b} 26)$, and that there is no reasoning, or deliberation, about ends, but only from them ( $E E$ $2.10,1227 \mathrm{a} 5-13 ; 2.11,1227 \mathrm{~b} 23-5)$, or about what is conducive to them ( $N E 3.3,1112 \mathrm{~b} 11-12)$, may seem to speak unequivocally against the view that wish is a reasoned desire. ${ }^{8}$ But, as the exegetic discussion testifies, the textual evidence for the latter thesis appears notoriously inconsistent, leaving it open that reasoning can be about ends of action. ${ }^{9}$

But even if the textual evidence were more unequivocal in this regard, it would not be decisive for the question whether or not wish is a reasoned desire. For the claim that we can 
deliberate about ultimate ends of action may be understood in two completely different ways. On one reading, the claim is that deliberating about the end produces a desire which is derived from reasoning alone, and not from any other desire or evaluative attitude. On this reading, reasoning is what ultimately motivates the pursuit of the end. But on another reading, short of producing the desire, deliberation articulates the desired object in terms of an action-guiding conception of the good and figures out how to achieve it in the particular circumstances. But for such reasoning to be motivationally efficacious, it must invoke a basic desire already present in the agent. Only the former reading lends support for the view that wish is a reasoned desire in the sense of being generated by deliberation. For, on the latter reading, the claim amounts to nothing more than that deliberation forms an action-guiding conception of the human good, as a prerequisite for satisfying wish. ${ }^{10}$

In fact, one of the main pieces of evidence for the view that wish is generated through reasoning lends itself more naturally to the latter reading. ${ }^{11}$ Discussing the causal conditions for animal locomotion in $D A 3.10$, Aristotle frames the discussion by asking whether the moving cause of animal locomotion is either desire or cognition, the latter of which comprises both perceptual cognition and reason ( $D A 3.10,433 \mathrm{a} 9-10)$. In what follows, Aristotle leaves us in no doubt that both desire and cognition jointly move the animal (433a13-14). This goes for specifically human cognition too. For when it comes to reason (vov̂s), it is obvious that it does

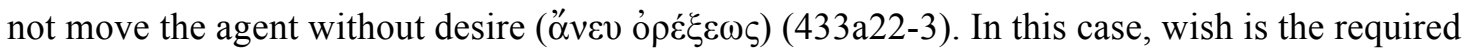
desire: 'For wish is a desire, and when anyone is moved in accordance with reasoning, he is also

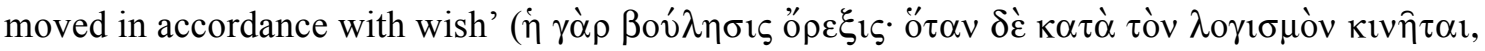

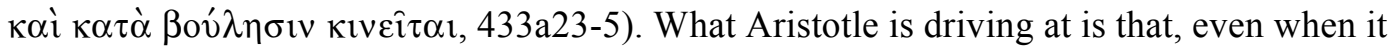
comes to reason's cognition about the good, a desire is required to provide the motivational push. But in that case, the desires of the non-rational part of the soul are not the proper kinds of desire to invoke. Instead, the desire of the rational part of the soul, i.e. wish, is invoked. ${ }^{12}$

The explanation of the striking feature that the rational part of the soul harbours a desire of its own, then, may just be that such a desire is required for the motivation to pursue the human good. For forming the conception of what the good for a human being is, and reaching a conclusion about what the good thing to do in the particular circumstance is, do not motivate action unless there is desire for that conception and that conclusion to invoke. So the textual evidence for the view that deliberation may be about the ultimate end of human pursuit may amount to nothing more than that, through such practical reasoning, the agent forms an actionguiding conception of the good.

I now turn to what I take to be the main contenders in the debate about the nature of wish. Still the most influential option is the intellectualist view, according to which reasoning 
actually produces wish. According to this view, wish is a desire of the rational part of the soul, which is basic in the sense that it is not derived from any other desire, or evaluative attitude. But in another sense, wish is not a basic desire, since it is derived from reasoning. So on the intellectualist view, reason on its own motivates action in virtue of producing a desire through reasoning.

Support for the intellectualist interpretation is gathered from the fact that Aristotle does not take an exclusively instrumentalist view of deliberation. The advocates of the intellectualist interpretation correctly point out that he does not confine deliberation to figuring out what to do as a means to obtaining a certain end. Instead, deliberation can also establish what should be done for its own sake. ${ }^{13}$ Aristotle singles out actions, which are intrinsically choiceworthy, namely virtuous actions such as acting justly, temperately or courageously ( $N E 2.4,1105 \mathrm{a} 28$ 33). The suggestion is that deliberation can bring about desires for these actions. For instance, when a person desires to act courageously and deliberates to the conclusion that in this particular situation a certain kind of action, e.g. speaking out, is the courageous thing to do, she desires to speak out for its own sake. It is, at least, awkward to say that the person's action of speaking out is a means to acting courageously. ${ }^{14}$

But this kind of case does not show that the basic, motivating desire is produced by reasoning. For speaking out is just an instance of courageous action in the particular situation. In another situation, speaking out may not be the courageous thing to do. Hence, in the above case, deliberation does not bring about the desire to act courageously, but merely the desire to speak out. But that means that the motivation to speak out is derived from the desire to act courageously.

To support their contention, advocates of the intellectualist interpretation limit their case further. What they have in mind are cases of deliberating about what actions are good in the sense that they are constitutive, or parts, of the supreme end, namely the good life or happiness. ${ }^{15}$ These actions are precisely the virtuous ones (NE 1.7, 1097a34-b5). Since virtuous actions are constitutive of happiness, they are neither means to the good life nor instances of good action depending on the particular circumstances. Instead, virtuous actions are always good and always pursued for their own sake. For instance, courage being a virtue, acting courageously is desired for its own sake. Moreover, wish is singled out as the reasoned desire for these good actions. Hence, if a person deliberates to the conclusion that acting courageously is a good thing to do, then deliberation produces the wish to act courageously, and deliberation thus motivates courageous action by producing this desire.

It may first be questioned whether this really is an instance of deliberation in Aristotle's sense. For, according to him, deliberation is a species of reasoning which is geared to action, 
and the conclusion of an exercise of deliberation must be such that the agent believes that it is within her power to act on it (NE 3.3,1112a30-4). For one thing, if a person is to act on the conclusion of an exercise of deliberation, it must be specific enough to be realisable. The conclusion that it is good to act courageously is hardly specific enough to be productive of action in that immediate sense.

But even if such reasoning is not directly productive of action, all the intellectualist case requires is that such reasoning can produce basic desires. So regardless of whether it is a case of Aristotelian deliberation at all, or perhaps an incomplete sequence of such, reasoning to the conclusion that acting courageously is a good thing to do can still produce the basic desire for courageous action, which in turn may serve as a starting point for an action-producing exercise of deliberation. In that case, it could be argued, the ultimate source of motivation lies in reasoning.

However, all this case shows is that reasoning can form a conception of goodness. Such reasoning may amount to nothing more than articulating the scheme of values already desired by the agent. But the intellectualist case requires that an agent can form a conception of goodness through reasoning without appeal to values already desired by the agent. The idea is that the conception so formed produces desires in the agent rather than reflecting desires she already has. For instance, reasoning to the conclusion that acting courageously is constitutive of goodness is supposed to instil in an agent who has no prior desire to act courageously a desire for courageous action for its own sake.

The question now is how this reasoning process is supposed to meet the intellectualist requirement. The obvious thing to appeal to are the reasons in favour of a certain conception of goodness. Again, these reasons must not include, or appeal to, values already desired by the agent. Since Aristotle conceives of virtuous activity as the good for a human being, a candidate suggests itself, namely Aristotle's function argument, which says that the good for a human being is virtuous activity because such activity fulfils the specifically human function, or nature (NE 1.7, 1097b24-1098a18).

But how is the function argument supposed to be motivationally efficacious? If the idea is that the argument can change the agent's conception of goodness, and make her pursue the good on that revised conception, then an account is required of how that is supposed to happen. For instance, if the idea is that the mere understanding of the reasons suffices to revise one's conception of the good, then one would like to know what those reasons are - desired values excluded. For the sake of the argument, let us grant that the function argument succeeds in establishing that virtuous activity fulfils the specifically human function. But even so, the argument could motivate only a person who finds fulfilment of human nature desirable. If 
appeal were made to the view that it is good to fulfil one's own nature, the argument would just beg the question. It is therefore more natural to understand the function argument as a dialectical argument, which articulates and justifies this view of the human end. ${ }^{16}$

One reply is to say that not agreeing with the conclusion of the function argument is indicative of failing to understand it. Admittedly, Aristotle thinks that there is a truth about what the good for a human being is, and that people may, and do, fail to grasp it. So perhaps the virtuous person endorses the conclusion of the argument precisely because she has the proper cognitive prerequisites. But then we are back to the question through what kind of cognition the virtuous person comes to endorse the conclusion. As long as the advocates of the intellectualist interpretation do not make this kind of cognition explicit, it is difficult even to take a stand on it. ${ }^{17}$

Jessica Moss has recently worked out a formidable alternative to the intellectualist interpretation. According to her empiricist interpretation, what an agent desires, and is motivated to pursue, is what she perceptually experiences as good. ${ }^{18}$ On Moss's interpretation, wish is a rational desire for the ultimate end of human pursuit, since reason is required to conceptualise that end. But even if wish is rational in this sense, the source of motivation is in the non-rational part of the soul. For the motivational force is derived from what this part of the soul experiences as pleasant. So wish motivates the pursuit of what is good for human beings, because it is pleasant to the agent.

Moss is unorthodox in assuming on Aristotle's part a distinctively Humean, and modern, notion of reason as motivationally inert. ${ }^{19}$ For on her interpretation the rational, or reason-possessing, part of the soul is stripped of desires and values of its own. Instead, it is confined to the power of reasoning. To underpin this Humean reading, she even argues that wish belongs to the non-rational part of the soul, fairly unequivocal evidence to the contrary notwithstanding (DA 3.9, 432b5-6; Top . 4.5, 126a13). ${ }^{20}$ So even as far as the pursuit of the human good is concerned, the source of motivation is the non-rational part of the soul.

Moss is not particularly detailed about how wish motivates the pursuit of the human good, but the idea seems to be that the virtuous person is motivated in her pursuit of the good by the pleasure she takes from perceiving her own excellent activity $(2012,215)$. Since Aristotle characterises the ultimate end of human pursuit, the activity of the soul in accordance with virtue, as the most pleasant state, and pinpoints pleasure as what perfects the activity (NE 10.4, $1174 \mathrm{~b} 20-3)$, it may seem as if the human good in part consists of pleasure, or at least that pleasure plays an indispensable part in motivating its pursuit.

However, even if pleasure (and pain) may play an indispensable role in habituating the developing individual to virtue, I see no compelling evidence that Aristotle makes the pursuit of 
virtuous activity conditional on pleasure, even as far as the pleasure proper to virtuous activity (oikcí $\alpha \dot{\eta} \delta o v \eta$ ) is concerned. First, even if the ultimate end of human pursuit is both pleasant and good for the virtuous person (EE 7.2, 1235b32-3), pleasure is not constitutive of the human good. In Aristotle's account of the relation between pleasure proper to the virtuous activity and the virtuous activity itself, that pleasure arises only in so far the activity is virtuous ( $N E$ 10.4, 1174b14-23). Since the proper pleasure is taken in an activity, which already is virtuous, it cannot be constitutive of it. ${ }^{21}$

Secondly, pleasure proper to virtuous activity is not even what motivates the pursuit of it. For it is part of Aristotle's conditions for virtue that the virtuous activity is chosen for its own sake $(N E 2.4,1105 \mathrm{a} 32)$. As far as pleasure is concerned, he explicitly points out that we do not choose activities like seeing, remembering, knowing and virtuous activity because they are pleasant: 'for we would choose these even if no pleasure arose from them' (NE 10.3, 1174a411). He puts the case counterfactually in order to pinpoint that, despite the fact that pleasure always follows upon virtuous activity, it is not for the sake of pleasure that the virtuous person chooses it.

A completely different reason for assuming such a central role for pleasure in the specifically human pursuit is that pleasure and pain play a central role in explanations of animal, as well as human, locomotion. For pleasure and pain are crucial in the physiological mechanism ultimately causing the limbs to move in the appropriate ways. ${ }^{22}$ But with regard to the chief good for a human being, i.e. virtuous activity, this kind of explanation is misplaced. This is not to deny Aristotle's hylomorphism, or that virtuous activity may involve bodily movements. But with regard to the explanation of the human pursuit of the good, the explanation should stick to the conceptual framework germane to that domain. ${ }^{23}$

Finally, David Charles offers what may seem to be a further option, although he does not take an explicit stand on the motivational issue (see Charles 2006, 31-3, 35). Charles' suggestion is that Aristotle assumes mental states which are both cognitive and desiderative. According to this account, cognising something as good implies desiring it, and desiring something implies cognising it as good. As far as wish is concerned, the idea is that, when practical intellect cognises something as good, the agent also desires it without assuming any prior desire providing the practical intellect with a starting point. The idea, rather, is that, when the practical intellect cognises something as good, that mental act is intrinsically desiderative, and that rational desire, or wish, is manifested in precisely such hybrid states.

Apart from the fact that there is no direct textual evidence for the claim that wish is

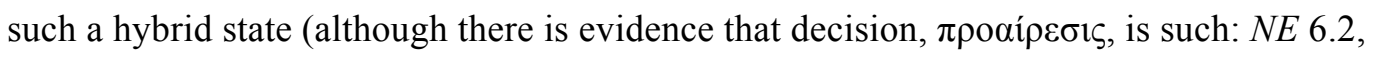
$1139 a 23 ; 1139 b 4-5)$, Charles' view that the cognition and the desire are two aspects of the same 
mental state is mute in the question what ultimately motivates an action. The account is compatible both with the view that the basic, motivating desire is reasoned, and with the opposite view that the source of motivation is an unreasoned desire. On the former view, one would like to see an account of that inherently desiderative cognition. On the latter view, again, the account does not explain whence the unreasoned desire for the good originates. When an agent intellectually cognises and desires something as good, this desire may just be derived from a desire present independently of that cognition.

\section{Wish and the human good}

I now turn to the evidence that wish has the teleological function of motivating the pursuit of the specifically human good in terms of virtuous activity. The textual evidence is gathered from the Ethics, and particularly from NE 3.2-4 and EE 2.10. Both sections are concerned with making

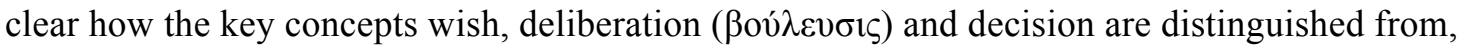
and related to, one another. Since Aristotle explicitly distinguishes wish from the other two species of desire, namely appetite and spirited desire (EE 2.10, 1225b25-6), it must be a specific notion of wish he has in mind here. This tripartition of the basic desires, moreover, is in evidence elsewhere (DA 3.9, 432b5-6).

Admittedly, even in these main sources, the term 'wish' is used in a broader sense. In $N E$ 3.2, Aristotle points out that decision is not about ends, not about impossible things and not about things which are not in the agent's power to bring about (NE 3.2, 1111b20-30; see also $E E$ 2.10, 1225b32-6). To that end, he contrasts decision with wish. For we may wish for ends like happiness and health but not decide about them. The example that we may wish for happiness but not decide to be happy fits the specific sense of wish, for happiness is another way to describe the ultimate end of human pursuit. Health is less obviously related to the chief human good in terms of virtuous activity, but perhaps health is conducive to happiness in the sense of being a precondition for virtuous activity. But it is even more difficult to see impossible things, such as immortality, or things not in the agents power to bring about, such as the victory of an athlete or the success of an actor in a play, as conducive to virtuous activity. Perhaps these examples of objects of wish can be explained away by the fact that, in this particular passage, the primary concern is to pinpoint the scope of decision, and the examples are invoked as contrast cases with little bearing on Aristotle's specific notion of wish - but I shall not press the point.

In the end, I do not lay claim to conclusive and unequivocal textual evidence for my interpretation. But my interpretation is not merely compatible with the textual evidence, but is in fact also suggested by it. Together with the explanatory force of assuming wish to be a basic 
desire for the human good, these pieces of evidence make a strong case for the claim that wish has the teleological function of motivating the pursuit of the human good.

Aristotle is explicit about the fact that wish is a desire for the good (NE 3.4, 1113a1516; EE 2.10, 1227a28-31; Top. 6.8, 146b5-6; Rhet. 1.10,1369a2-4) and that it is a desire for the end (NE 3.2, 1111b26-9; 3.4, 1113a15; 3.5, 1113b3). He is also explicit about what the good for a human being consists in, namely the activity of the soul in accordance with virtue, which brings human nature to its fulfilment (NE 1.7, 1098a7-18). The task now is to piece these remarks together to establish that wish motivates the pursuit of the human good in precisely that sense.

This function of wish is hinted at in the opening pages of the Nicomachean Ethics. Aristotle points out that, to stop an infinite regress being generated, there must be an ultimate

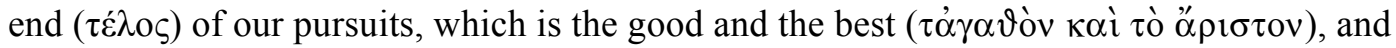
which we wish for its own sake (ö $\delta$ ' $\alpha$ vìò $\beta o v \lambda o ́ \mu \varepsilon \vartheta \alpha)(N E$ 1.2, 1094a18-22). The

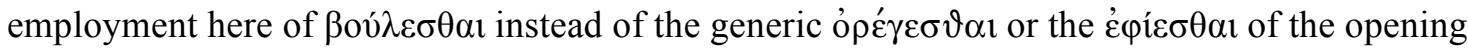
lines (NE 1.1,1094a1-3) is not accidental. Since the point concerns the ultimate end of our pursuits, Aristotle invokes a specific desire, which he later, in Book 3, articulates in precisely these terms, namely as being for the end of pursuits $(3.2,1111 \mathrm{~b} 26-30)$ and for the good (3.4, 1113a15-6). By contrast, the objects of desires of the non-rational part of the soul are not accounted for in terms of ends, let alone in terms of the ultimate end.

A crucial piece of evidence for the view that the function of wish to is motivate the pursuit of the specifically human good is in $E E 2.10$. This chapter, just as $N E$ 3.2, is concerned with articulating what decision is, and how it is related to deliberation and to wish. But it is considerably more detailed than the treatment in $N E 3.2$, and also contains an account of the end which we may wish for but neither deliberate nor decide about. To make his point clear, Aristotle introduces an analogy (EE 2.10,1227a18-31). He claims that there is a teleological order, such that ends of pursuits are good by nature ( $\varphi v ́ \sigma \varepsilon 1)$. For instance, the ends of medicine and of warfare, namely health and victory respectively, are good by nature. However, people may go against the teleological order. For through a twist, or a turning from the natural course

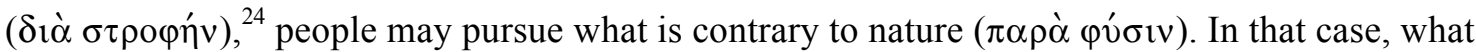
is achieved is not the good but the apparent good. For instance, although knowledge of medicine can be employed to produce the opposite of health, that is, disease, medicine is not by nature knowledge of how to bring about disease. Employing the art of medicine is according to nature

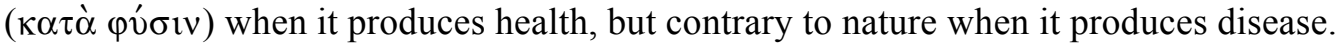

The purpose of introducing the example of medicine and health is to explicate the teleological function of wish. For 'similarly [sc. to the case of medicine and health], wish is by 
nature for the good, but contrary to nature for the bad too, and one by nature wishes the good, but contrary to nature and, through a twist, one wishes the bad too'. ${ }^{25}$ Aristotle here puts emphasis on the fact that wish is a desire, which by nature is for the good ( $\dot{\eta} \beta$ ov́ $\lambda \eta \sigma ı \varsigma ~ \varphi v ́ \sigma \varepsilon \imath$ $\mu \grave{\varepsilon} v \tau o \hat{v} \dot{\alpha} \gamma \alpha \vartheta 0 \hat{\varepsilon} \dot{\varepsilon} \sigma \tau i)$. The point that wish by nature is for the good, although contrary to nature wish is for the bad too, strongly suggests that what wish is for by nature is what in fact is good, and not whatever the agents happens to think is good. So the point is not just that there is a real good for human beings to pursue. In addition, there is an inclination towards it in terms of a particular kind of desire, which by nature is for that good. So according to this analogy, wish is by nature for the good and what motivates its pursuit.

But even if wish by nature is a desire for the good, it does not immediately follow that the object of wish is a single specific good. Perhaps wish is for a whole range of objects, which are truly and determinately good, but without these objects being constitutive of, or conducive to, a chief human good in terms of virtuous activity. In addition, it is not obvious that the object of wish is determined by human nature, quite regardless of what people may happen to think is their own good, or what they happen to pursue as good. Instead, wish could as well be for the good relative to the individual, and her priorities.

However, Aristotle's account of how we may pursue something contrary to nature is put

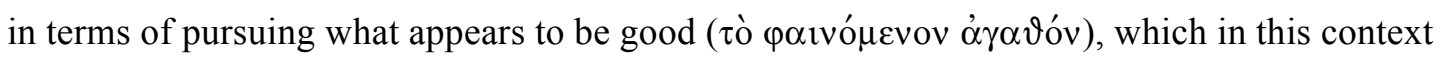
must imply what merely appears to be good without being so (EE 2.10, 1227a21-2; cf. Top. 6.8, 146b36-147a4; MA 700b28-29; Metaph. 17, 1072a27-8). Even if, in this context, he does not state that there is a natural object of wish, or a natural good, it is sensible to assume that there is a fit between wish and its object in the sense that wish is for what in fact is good for human

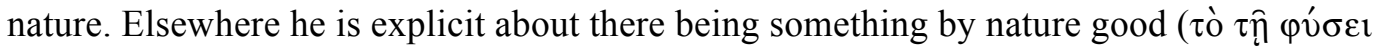
$\left.\dot{\alpha} \gamma \alpha \vartheta{ }^{\prime} v\right)$, namely what is good and pleasant to the good person ( $\left.\tau \hat{\varphi} \sigma \pi \mathrm{ov} \delta \alpha \dot{i} \omega\right)$ (NE 9.9, 1170a14-16).

The main evidence for the view that the object of wish is a determinate good, set by human nature, and not what people happen to think is their own good, can be gathered from the puzzle in $N E 3.4$ whether wish is for the good or for the apparent good. I elaborate on the puzzle, and on Aristotle's solution to it, in the next section, but for now I want to pinpoint that in the very set-up of the puzzle, which is presented as a dilemma, Aristotle takes it for granted that wish has an object which belongs to it by nature, quite regardless of what people may happen to think is their own good. The conclusion of the second horn of the dilemma is that the object of wish is what appears good to people, and that there is nothing wished for by nature ( $\mu \grave{\eta}$

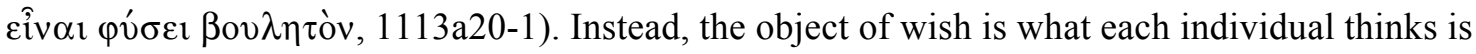


good. Aristotle dismisses the conclusion without argument, which is a clear indication that he takes it for granted that there is such a thing as the natural object of wish.

Moreover, in NE 9.4 Aristotle pinpoints that wish is for what is good for human rational nature specifically, namely to exercise virtues in accordance with reason. For in the account of how the virtuous person desires for his friend the same kind of good that he desires for himself, the object of wish is confined to what is good for human rational nature. That he has in mind wish as the specific desire for the good is clear from the context. He even depicts inferior people who cannot be friends with themselves as conflicted between what they have an appetite for

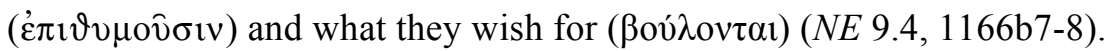

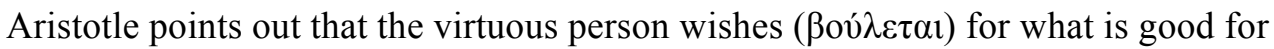
herself, and that she acts for her own sake, namely for the sake of the reasoning part of her soul

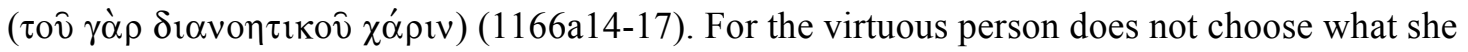
believes to be good for a different kind of nature, but what is good for the kind of being she actually is, which is to say that by which she thinks ( (1166a17-23). Choosing base pleasure, for instance, is to choose what is good for a different nature. Confining the object of wish to what is good for human rational nature, as opposed to her nutritive, reproductive or perceptual nature, also explains why Aristotle attributes wish to the rational part of the soul.

This idea is put even more clearly in the anonymous paraphrasis of the Nicomachean Ethics ([Heliodor.], in EN paraphr. 193, 33-7 Heylbut): ${ }^{26}$

For the reasoning part is what it is to be human, for the sake of which the good person does everything and pursues everything good, but for the sake of which the bad man does nothing. For the bad person does not have thinking as the end of his own activities, but base pleasure. For this reason, he does not wish what is good for himself for his own sake.

So the idea is that what is good for a human being is to exercise reason, and we may safely assume that the end referred to is the exercise of virtues in accordance with reason. When people choose what is not good for that part, they wish something that may be good for some other part of their soul but not for their true nature. But in that case, they do not wish for what wish by nature is designed to be for. So despite the fact that many people go wrong in their pursuit for the good, there is a robust sense in which wish is for what in fact is good for human beings. I conclude, then, that wish is a basic desire of the rational part of the soul, and that it has 
the teleological function of motivating the pursuit of a specific kind of end, namely the human good in terms of virtuous activity.

\section{Wish and representation}

The claim that wish has the teleological function of motivating the pursuit of the human good in terms of virtuous activity faces a challenge. For, as mentioned, Aristotle also has it that people wish for what they believe to be good, or what appears good to them (NE 5.9, 1136b7-8; Rhet. $1.10,1369 \mathrm{a} 2-3)$, which suggests that wish is for whatever people conceive of as good. But this seems to undermine my claim that wish has this teleological function. An easy way out would be to say that wish has this teleological function only in the ideal case, when things go according to the natural order. But when a person wishes for what she thinks is good for her, although in fact it is bad, she simply has no wish for what really is good for her.

However, Aristotle takes a view reminiscent of the Socratic idea that what people think they desire may in fact not be what they desire (Gorgias 466c9-468e5; Laws 9, 860d1-861d9). Applied to wish, the idea is that a person may wish for what she erroneously thinks is good, but still be motivated in that pursuit by the basic desire for what in fact is good. When she does so, she pursues, and may even obtain, what is not good, but unbeknownst to herself, she is motivated in her pursuit by the desire for what really is good.

My suggestion is that wish as the intentional state which motivates the pursuit of the good consists of a source of motivation in terms of a desire for the human good, and the representation of the good in terms of an action-guiding conception of the good. In case the representation of the good is erroneous, the agent will pursue the wrong things, but the source of motivation will still be the desire for the human good. This suggestion goes against the assumption that the desire-state is transparent to the agent in the sense that what the agent desires is confined to what she represents as good. But I think that there are several indications that Aristotle's notion of orexis and its species is not confined to such states. ${ }^{27}$

To begin with, the kind of mistake in the representation of the good at issue here is an erroneous representation of the ultimate end, or the chief good, and not a mistake about particulars. Aristotle pinpoints the difference between ignorance about the particular and ignorance about the universal in discussing the conditions for voluntariness in NE 3.1 (1110b281111a2). The bad person's ignorance about what one should do, and what one should abstain from, counts as ignorance about the universal ( $\left.\dot{\eta}{ }^{\prime} \alpha \gamma v o t \alpha \kappa \alpha \vartheta \hat{\gamma}^{\prime} \mathrm{ov}\right)$, namely concerning the advantageous ( $\tau \grave{\alpha} \sigma v \mu \varphi \dot{\varepsilon} \rho o v \tau \alpha$ ) or the good, and what is done from such ignorance is voluntary, and hence does not exempt the person from blame. A typical case of such ignorance is the lessthan-virtuous person's erroneous conception of the good as pleasure. But when pleasure appears 
good to her, she is not only ignorant about what the good really is, for she even believes what is not good to be good. That is, she is in a state of deception ( $\alpha \dot{\alpha} \alpha \dot{\tau} \eta)(N E 3.4,1113 \mathrm{a} 33-\mathrm{b} 2 ; E E$ $7.2,1235 b 25-9)$.

Before I defend the contention that even a person who has an erroneous conception of the good and pursues what is not good may unbeknownst to herself be motivated in her pursuit by the basic desire for what really is good, let me first turn to the analogous case of another kind of desire, namely appetite. For Aristotle explicitly puts forward the view that a person, who misrepresents the object of appetite and fails to fulfil it without realising it, is still motivated by the desire for the proper object of appetite. Of course, a person may go wrong in trying to satisfy an appetite when she mistakenly believes that a particular object will satisfy it. A thirsty person may desire a glass of liquid on the table but, on having a sip of it, realise that it is petrol. In this case, on having the sip, she realises that her belief about this particular glass of liquid was mistaken, and she is aware that her thirst was not quenched.

But in NE 3.11, Aristotle pinpoints another kind of mistake, in which the failure to fulfil an appetite is not transparent to the agent. In his account of the self-indulgent character, he

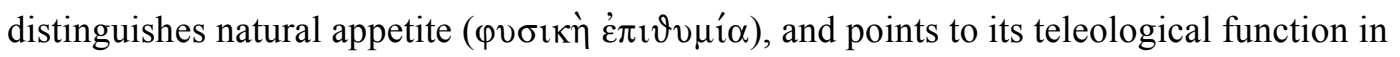
promoting the well-being of the organism. For instead of characterising appetite in the usual way as the desire for pleasure, Aristotle pinpoints two kinds of natural appetite, namely hunger and thirst, as desires for nourishment ( $\tau \rho \circ \varphi \eta)(1118 \mathrm{~b} 8-11)$. The way the self-indulgent person goes wrong in fulfilling these natural appetites is through over-consumption (1118b15-16). And just as nourishment hardly refers to the intentional object of hunger and thirst, so is the object of natural appetite couched in equally objective terms, without appeal to pleasure or to any experiential state. For to over-consume is 'to exceed the natural limit in quantity; for [the object

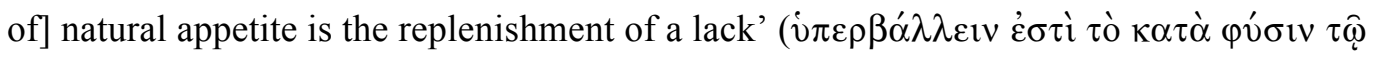

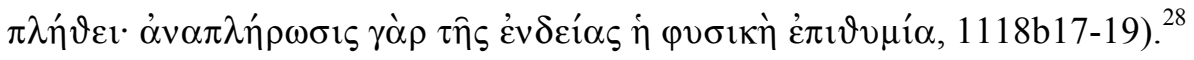

The idea is that, even if the self-indulgent person represents the food or drink as pleasant, whatever pleasure she gets from them is not the criterion of fulfilment. For the object of hunger and thirst is a determinate amount of food and drink proportionate to the deficient state of the body, ultimately accounted for in physiological terms. So the satisfaction-conditions for these natural desires are quite independent of whatever representation of the object the selfindulgent person has. That is, even if the self-indulgent person may think that she has satisfied her craving for food and drink, and done so with a vengeance, in fact she has failed to satisfy her natural appetites.

Nevertheless, even in the self-indulgent person, the natural appetite motivates her pursuit of food and drink. In the case of hunger and thirst, the ultimate source of motivation is a 
deficient state of the body, and the function of natural appetite is to alleviate that state. In other words, hunger as an intentional state derives its motivational force from the uneasy feeling due to a deficient state in the body, ultimately accounted for in physiological terms. The deficient state in the body gives rise to frustration, but this frustration does not itself supply any representation of how it may be relieved. The example allows us to distinguish between the source of motivation, which is insufficient on its own to prompt any action, and hunger as the intentional state which represents food, or even the particular kind of food, to be pursued. So hunger as an action-motivating state consists of this frustration, which is the ultimate source of motivation, and the representation of an object.

I now want to claim for wish a similar kind of distinction between the source of motivation and the representation of the good in terms of an action-guiding conception of the good. This distinction provides a framework for explaining how a person pursuing what appears good to her, although it is not good, may still be motivated by the desire for what really is good.

I first turn to Aristotle's handling of the puzzle in $N E$ 3.4. The puzzle concerns precisely the characterisation of wish and its object, and Aristotle's discussion of the puzzle constitutes the most explicit account of the topic in the entire corpus. The puzzle is presented as the question whether wish is for the good or for the apparent good ( (1113a15-16). The straightforward answer to the question is that in one sense wish is for the good, but in another sense for the apparent good. For all people wish for what appears good to them, but only what appears good to the virtuous person really is so.

The problem with this straightforward answer is that it does not do justice to the dialectic in $N E$ 3.4. For the question is presented as a dilemma, crucially invoking the notion 'object of wish' ( $\tau$ ò $\beta o v \lambda \eta \tau o ́ v)$ rather than sticking straightforwardly to 'the good'. The first horn of the dilemma is that, if we understand the object of wish, or what is wished for, as what really is good, then people who incorrectly choose as good what in fact is bad wish for what is

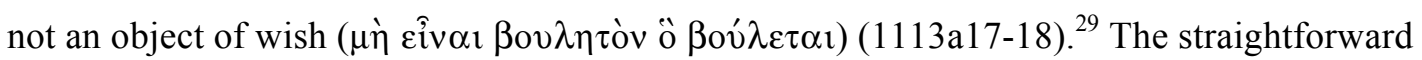
answer to the first horn is to reject the equation of the object of wish with what really is good. Instead, we should understand the object of wish as whatever the agent represent as good, quite regardless of whether it happens to be what really is good.

However, the straightforward answer does not catch the drift of Aristotle's reasoning. For, in the second horn of the dilemma, Aristotle challenges precisely the claim that the object of wish is whatever appears good to people. For, surprisingly, Aristotle dismisses out-of-hand

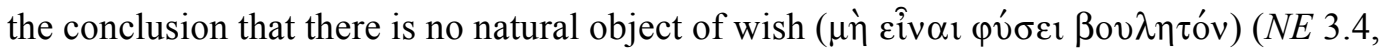
1113a20-1). Assuming the straightforward answer to the challenge of the first horn, one may have expected Aristotle to embrace the view that there is no natural object of wish, albeit there 
is something by nature good for human beings. This is what Aspasius expected. For, as Aspasius points out, since it is natural to think that the object of wish is precisely what a person takes to be good, the notion of a natural object of wish is not only obscure, it even seems dispensable, for all that Aristotle needs is a robust notion of something's being good by nature. ${ }^{30}$ And then he could straightforwardly state that both the virtuous and the inferior person wish for what they take to be good, or for what appears good to them, but that only the virtuous person wishes for what in fact is good.

Aspasius' worry is understandable, but there is a way of making sense of Aristotle's handling of the second horn of the dilemma. To begin with, if the point is merely to establish that only what the virtuous person represents as good really is so, then operating with a notion of the natural object of wish is confusing just in the way Aspasius thinks. But Aspasius may just miss Aristotle's rationale for this notion. A rationale for operating with this notion is to bring out the fact that in one sense wish is a desire for what really is good for a human being, and not for whatever the agent takes to be good. For the natural object of wish, or the object of wish

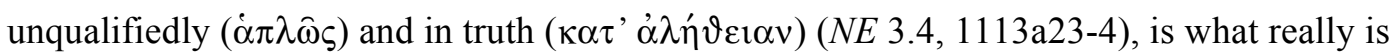
good. So even if the object of wish in another sense is whatever that appears good to the agent, Aristotle wants to bring forth the function of wish as motivating the pursuit of the human good, just as hunger and thirst have the function to motivate the pursuit of nourishment, however the agent happens to represent the object.

So my suggestion is that Aristotle distinguishes between wish as the basic desire for the specifically human good as the source of motivating its pursuit, and wish as the fully intentional state, in which a representation of the good gives that motivation a direction. On that distinction, the natural object of wish is precisely what wish in its teleological function is for, namely the human good. This distinction provides a framework for explaining how a person pursuing what appears good to her, although it is not good, may still be motivated by the desire for what really is good for her.

With this distinction in mind, let us revisit the first horn of the dilemma. For now the first dilemma turns out to be more of a genuine problem, or even a paradox. For if we take what the less than virtuous person wishes for (ô $\beta o v ́ \lambda \varepsilon \tau \alpha \iota$ ) to be what really is good, then it seems that he wishes for what he does not wish for. In order to disarm the paradox, a notion of an object of wish in terms of whatever appears good is called for. But there is still a sense in which even the less-than-virtuous person wishes for what really is good. For even if the less-thanvirtuous person has a mistaken conception of what is good for her, she is still motivated by the basic desire for the natural good. So Aspasius misses the drift of Aristotle's dialectic in NE 3.4, 
which is to make room for the possibility that even the less-than-virtuous person wishes for what really is good.

This distinction makes good sense of Aristotle's summary of the discussion in NE 3.4 $(1113 \mathrm{a} 22-6):^{31}$

Now if these views [i.e. in the dilemma] are not satisfactory, should we say that what is unqualifiedly and in truth the object of wish is the good, but to each individual [the object of wish is] the apparent [good]? So that [what appears good] to the virtuous person is [what] in truth [is good], whereas [what appears good] to the inferior person is any chance thing...

The answer to the rhetorical question is that, in one sense, the object of wish, namely the object of wish unqualifiedly and in truth, is what really is good, but that, in another sense, the object of wish is whatever appears good. So the upshot of the dilemma is to distinguish between the object of wish as what this desire is for by nature, and as what the subject represents as good. Again, the straightforward answer to the puzzle in NE 3.4 could have dispensed with the notion of a natural object of wish. Instead, it could have summarised the discussion by saying that the object of wish is what appears good to both the virtuous and the inferior person, but that only what appears good to the virtuous person really is good. But since this is not how Aristotle summarises the discussion, the straightforward answer makes poor sense of both the puzzle and its solution.

Further evidence for the Socratic view that people may not be aware of what they desire can be found elsewhere in Aristotle. In $N E$ 10.2, it is suggested that even people who pursue and obtain what they mistakenly believe to be good still have a desire for what really is their own proper good. This view is implied by a detail of Aristotle's assessment of Eudoxus' argument that pleasure is the good, since every creature, rational and non-rational alike, seeks pleasure. An objection to Eudoxus is that, even if all creatures seek pleasure, it is not obvious that they seek it as the good. Aristotle agrees with the objection insofar as non-rational animals are concerned, but dismisses it in the case of rational animals (1173a2-4). That is, he admits that it could be the case that non-rational animals do not seek the good, but he is adamant that rational animals do so. And against the potential objection that less-than-virtuous persons, like the bad person, may be on a par with non-rational animals in not seeking the good, Aristotle points out: 'similarly, in bad people too there is something by nature good, which is greater than what they

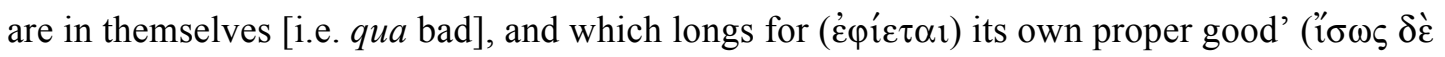

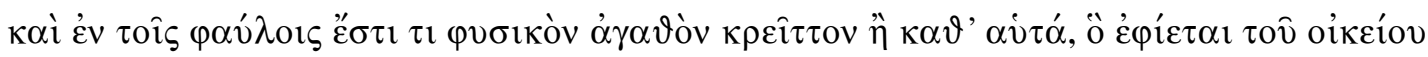


$\dot{\alpha} \gamma \alpha \vartheta 0 \hat{v}, 1173 \mathrm{a} 4-5) .{ }^{32} \mathrm{He}$ does not explicitly say that bad people wish for their proper good, but he attributes to them a desiderative attitude towards it, although they do not have a correct action-guiding conception of the good.

Moreover, in his account of the miserable state of bad people in NE 9.4, Aristotle points out that bad people hate themselves, are full of remorse, and even consider suicide, on account of a conflict between what they have an appetite for ( $\dot{\varepsilon} \pi \vartheta \vartheta \mu o v \sigma v)$ and what they wish for

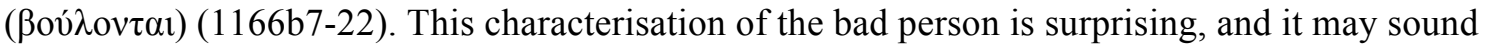
as if the bad character is conflated with the akratic one. But the idea is that, although the bad person acts on her reasoned view of what she erroneously believes to be good $(7.8,1151 \mathrm{a} 5-7)$, she nevertheless has a wish for what in fact is good. Otherwise it would be hard to make sense of the bad person's conflict. So the point is not just that she is turned away from the real good, and that she fails to fulfil her human nature. For even the bad person has a wish for what really is good for her, which she fails to satisfy.

The explanation of the bad person's failure is her mistaken representation of pleasure as the good. For even if she obtains pleasure, she does not obtain what her wish is for by nature. So

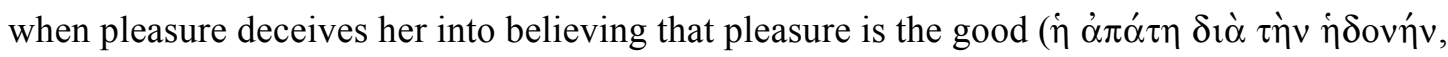
$N E 3.4,1113 \mathrm{a} 33-4)$, she is deceived in the attempt to fulfil her wish. In a certain sense, what she obtains is not what she wanted. So the claim that human beings have a wish for the real good holds even for those who do not pursue it in the first place, even if they mistakenly think that they manage to obtain the good. ${ }^{33}$

A worry for my interpretation is that Aristotle does not explicitly state that a person who pursues the good on an erroneous conception of the good fails to fulfil her wish specifically. But in $E E$ 1.5, he articulates the idea that there is a desire for the good life that tends to be difficult to satisfy. Aristotle points out that: 'While there are many other things about which it is not easy to judge correctly, this is even more the case with what most people think is the easiest, and what they think anyone knows, namely what of the things in life should be chosen, and what would fulfil one's desire if obtained' ${ }^{34}$ He speaks of the fulfilment of

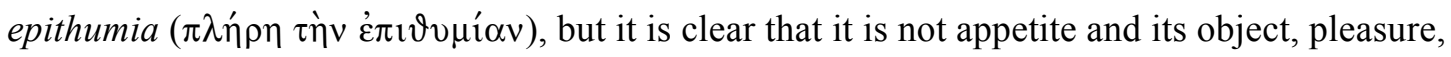
that are at issue. Epithumia here is used in a generic way, synonymous with orexis. But what he explicitly has in mind is a desire for happiness, or the good life. For, considering the subject matter at issue, how to lead a good life, it is the fulfilment of the desire for the human good that he has in mind. What makes it difficult to fulfil this desire is that people tend to misconstrue what the good life is.

A difference between wish and appetite is that, even when the truly good is achieved, the virtuous person will continue to desire it, and will be motivated by this desire to carry on 
with the virtuous life. So the source of motivation in the virtuous person is not a deficiency in her present state. This, I think, is the reason Aristotle characterises wish as a painless desire

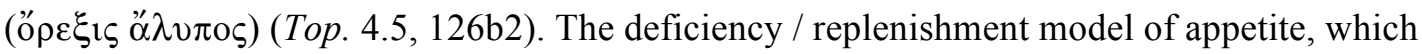
makes pain and pleasure indispensable, does not apply to wish.

But people who have not yet achieved the truly good are in a deficient state, which in their case is a source of motivation. For instance, take a person who thinks that excessive bodily pleasure is the ultimate good, and that the sybaritic life will make her happy. If eventually she achieves this kind of life, but finds out that she is not content, and is perhaps even bored and disgusted with the kind of life she leads, she may try to revise her view of what the good life comes to and of what kind of life makes her happy. But the explanation of why she is prepared to reject her previous view is precisely that the desire for her own proper good, which is the ultimate source of motivation, is not satisfied. So although a representation of the good is required in order to give the agent's want a direction, it is ultimately against her desire, which by nature is for her own proper good, that any conception of the good is tested.

The claim that wish by nature is for the specifically human good, then, is reconcilable with the idea that wish is for whatever people think is good. The explanation is that acting on a desire requires a representation of its object, and that we may go wrong in forming this representation. But what in fact fulfils the desire is determined by what teleological role the desire in question has.

\section{Reasoning and the elusive human good}

A more general challenge for the view that wish has the teleological function of prompting the pursuit of the human good is that so few people pursue what is good for them, and that even fewer people obtain it. The track record of wish may seem too poor for it to have such a natural function. Compare this situation with the workings of one of the desires of the non-rational part of the soul, namely appetite. Appetite is a desire for bodily pleasure, and it explains the pursuit of nourishment, which promotes the survival and well-being of the organism. A non-rational animal, as well as a human being, may go wrong in the pursuit of nourishment, taking pleasure from the wrong kind of things. Nevertheless, for the most part this mechanism is reliable, to the benefit of the animal. So if wish is a basic desire which explains the pursuit of the human good, why is this mechanism less reliable? Unless there is an explanation of why people to such a large extent fail to obtain their own good, there is reason to think that wish, after all, is not a basic desire, but an acquired desire derived from the particular conception of the good which the subject has formed. In that case, the teleological function of wish seems less direct, and failing 
to obtain the good should not count as a failure to fulfil wish, but merely as a failure to bring human nature to fulfilment.

However, the poor track record of wish can be explained by its more demanding, and thus more elusive, object. For the object of wish requires a different kind of representation, which it is more difficult to form, than in the case of appetite. In particular, what distinguishes this specifically human desire from that shared with non-rational animals is that its object cannot be represented by means of perceptual cognition. The reason for this is that the good for a human being, namely virtuous activity, is a non-salient feature in the world, which cannot be spotted in the way that, for instance, objects of sense perception are discriminated by the relevant sense organ. The good for a human being is a complex value, and a matter of the way one leads one's life, what activities one is engaged in, what attitudes one takes towards oneself and other people, and so on.

Satisfying the desires of the non-rational part of the soul, by contrast, requires mere perceptual cognition. Even if the pursuit of the object of appetite requires that it be represented in some way or other, no reasoned conception of it is required. Evidence for this is that nonrational animals pursue, and obtain, pleasure without any reasoning at all. So both non-rational animals and human beings can satisfy their desire for drink, say, without recourse to reason. For they can manage that on the basis of other cognitive capacities such as sense-perception,

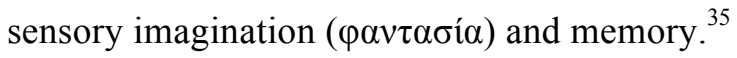

The good for a human being is not only more elusive than, for instance, the object of appetite, it is also such that a person can live without obtaining any, or only little, of it. By comparison, satisfying the appetite for drink and food is a condition for the survival of the organism. Appetite for drink and food, therefore, is triggered right from birth. Thirst, for instance, is a function of the biological organism and arises when the fluid balance in the body is disturbed. The desire for the good, by contrast, does not have the same kind of biological function and is not triggered by a disturbance in the organism. Instead, wish is a desire for a value proper to the rational nature of human beings, and pursuing it requires that the sense of this value is aroused, cultivated and trained. In view of the fact that the good is such a complex value, developing this sense is not instinctive. Moreover, acquiring the proper conception of the good is a matter of experiencing the satisfaction of wish in good actions, and of forming, and refining, the conception of the good on the basis of that experience, the process being potentially open-ended. ${ }^{36}$

It is precisely this requirement of a reasoned representation of its object that has led scholars to assume that wish is a reasoned desire, and that the object of wish is determined by the subject's conception of the good. But by separating the representation of the object in terms 
of an action-guiding conception of the good, from the source of motivation in terms of a desire which by nature is for the human good, there is no need to embrace this assumption. Instead, what distinguishes wish from appetite with regard to reason is the kind of representation required for the pursuit of its object. For the human good cannot be spotted by means of senseperception, but requires a representation based on reason's cognitive resources. ${ }^{37}$

Evidence for the elusive character of the human good can be gathered from Aristotle's discussion of the common views about the human good, or happiness. For although everyone agrees that the human good, or happiness, is the most choiceworthy thing, people disagree about what it is. Moreover, most people mistakenly assume that it is to be found among obvious and

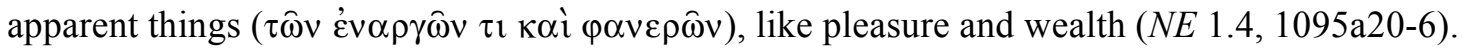
Pleasure, as has been mentioned, is a common source of deception concerning the good (NE 3.4, 1113a33-b2; $E E$ 7.2, 1235b25-8). In $E E$ 1.5, as we have seen, Aristotle pinpoints the assumption that it is easy to find out what one should choose in life as a source of mistakes (1215b15-18). As he discards certain erroneous conceptions of the happy life, he points out that the good in life escapes those searching for it (1216a9-10). And even if one manages to convince that the virtuous life is the best, people may nevertheless pursue the virtuous life in the wrong way, and for the wrong reasons, such as power, reputation and the wrong kinds of pleasure (1216a15-27).

But one may still wonder why the ultimate end of human life is so hard to come by. From the point of view of the design of the world, it may seem surprising that human beings cannot rely on instincts in the pursuit of their end. Part of the explanation is provided by an analogy in De Caelo 2.12. Aristotle sets out to solve a puzzle concerning the movements of the heavenly bodies: Why is the increase of the number, and of the irregularity, of the motions of the heavenly bodies not proportionate to the distance from the fixed stars? For whereas the fixed stars move only with one motion, the planets, which are supposed to be closer to the fixed stars than the sun and the moon, nevertheless move in more complex ways than the sun and the moon (291b28-292a3).

Setting aside the obsolete astronomical assumptions behind this puzzle, in his suggested solution of it, Aristotle points out that in addition to the relative distance from the fixed stars, we also need to take into account the relation between the degree of perfection of each kind of body, and the nature of their end. Since the fixed stars are in a perfect state in terms of circular movement, they do not need to undertake any action to achieve their perfection. But the less than perfect bodies must undertake action in order to achieve their ends. However, depending on how far from the highest end their specific end is, they need to undertake more or fewer actions, and of varying complexity. The idea is that some bodies have lower-level ends, which are 
achieved by fewer and simpler actions. The sun and the moon have simpler ends than the planets, the earth has an even simpler end than the sun and the moon (292a22- b10).

Crucial for my argument is the analogy between the movements of the heavenly bodies and those of bodies in the sublunary world. For the analogues to the planets in the sublunary world are animals and plants. Of these, it is human beings that are involved in the most numerous and complex actions. The reason is that the human end is closer to the highest end, or to divinity. There is a multiplicity of goods conducive to the human good that human beings have to act on. This condition is consistent with there being one single end for human beings, it is just that reaching it is more roundabout than in the case of the other animate things. By comparison, plants and non-rational animals reach their ends through a lesser number of actions. A plant, for instance, is involved only in one kind of 'action', namely growth. Since the steps to their ends are fewer and simpler, it is little wonder that they by and large achieve their ends. But in comparison to the human end, their ends are much farther from the highest end (292b13-25).

Aristotle does not use the analogy in De Caelo 2.12 to suggest that the more complex course of actions required for achieving the human good explains why human beings are less successful in achieving their end. Nor does he in any way relate it to action-motivating desires in general, or to the specifically human desire for the human good in particular. But he does suggest that human species is more ambitious in setting out for a higher end which is more demanding to achieve. For human beings have within them a divine element that makes them go for the highest end, however difficult to achieve (see also PA 2.10, 655b37-656a8). So he at least provides a framework for explaining the situation that human beings have a basic desire for the human good, and that even so it is few, if any, who achieve that end.

In the analogy, Aristotle seems to have the exclusive notion of the human good in terms of theoretical thinking, or contemplation, in mind. But even with regard to character virtue the end is demanding. Deliberating about what the virtuous and good thing to do in a particular situation is may involve considering both what virtue actually is, and how it is to be achieved in the particular situation. Take a specific good action, such as a courageous action. If a person wants to act courageously, she must consider what it is to be courageous in terms of what the demands of courage really are, and what the particular situation demands of her in this regard, before coming to the conclusion that in this particular situation speaking out, say, is the courageous thing for her to do. It is easy to see that there are many pitfalls in reaching that conclusion.

This should suffice to underpin the importance of the role played by reasoning in human pursuit of the good. Practical wisdom ( $\varphi \rho o ́ v \eta \sigma ı)$ ), at any rate, is a condition of virtue, and crucially involves deliberative prowess. Hence Aristotle assigns to reasoning a substantial role 
in producing virtuous action, but without implying the non-Humean claim that basic desires can be brought about through reasoning, or through any other kind of cognition. Instead, it is a distinctive trait of his moral psychology that the reason-possessing part of the soul has basic desires of its own, which cannot be reduced to, or derived from, the desires of the non-rational part. This source of motivation is characteristic of human beings. Hence, explanations of the pursuit of the human good need not appeal to desires of the non-rational part of the soul, although they must appeal to unreasoned desires. Furthermore, on the view that the natural good for a human being is a complex, hard-to-get value, and that deliberation is the reasoning process through which it can be obtained, practical reasoning is not merely a matter of figuring out the means to achieve whatever we happen to want. To the contrary, practical reasoning in its proper use is a matter of considering how we are to lead our lives in order to fulfil not only our nature, but even our innermost desires. ${ }^{38}$

\section{References}

Bobzien, S. (2014), 'Choice and Moral Responsibility (NE iii 1-5)' in R. Polansky (ed.), The Cambridge Companion to Aristotle's Nicomachean Ethics (Cambridge), 81-109.

Burnyeat, M. (1980), 'Aristotle on Learning to be Good' in A. Rorty (ed.), Essays on Aristotle's Ethics (Berkeley), 69-92.

Charles, D. (2006), ‘Aristotle's Desire' in V. H. Hirvonen, T. J. Holopainen and M. Tuominen (eds.), Mind and Modality: Studies in the History of Philosophy in Honour of Simo Knuuttila (Leiden), 19-40.

Cooper, J. M. (1975), Reason and Human Good in Aristotle. Cambridge, Mass.

__. (1988), 'Some Remarks on Aristotle's Moral Psychology', The Southern Journal of Philosophy 27 (Supplement): 25-42.

_- (1996), 'Reason, Moral Virtue, and Moral Value' in M. Frede and G. Striker (eds.), Rationality in Greek Thought (Oxford), 81-114.

Corcilius, K. (2008), Streben und Bewegen: Aristoteles' Theorie der animalischen Ortsbewegeung. Berlin / New York.

Gotthelf, A. (2012), Teleology, First Principles, and Scientific Method in Aristotle's Biology. Oxford.

Grant, A. (1874), The Ethics of Aristotle. Vol. 2. London. 
Irwin, T. H. (1975), 'Aristotle on Reason, Desire, and Virtue', The Journal of Philosophy 72: $567-78$.

__. (1978), 'First Principles in Aristotle's Ethics' in P. E. French, T. E. Uehling and H. K. Wettstein (eds.), Studies in Ethical Theory. (Midwest Studies in Philosophy 3.) (Minnesota), $252-72$.

Lorenz, H. (2006), The Brute Within: Appetitive Desire in Plato and Aristotle. Oxford.

_- (2009), 'Virtue of Character in Aristotle's Nicomachean Ethics', Oxford Studies in Ancient Philosophy 37: 177-212.

Majithia, N. (2006), 'Function, Intuition and Ends in Aristotle's Ethics', Ethical Theory and Moral Practice 9: 187-200.

Mele, A. R. (1984a), ‘Aristotle’s Wish', Journal of the History of Philosophy 22: 139-56.

__. (1984b), 'Aristotle on the Roles of Reason in Motivation and Justification', Archiv für Geschichte der Philosophie 66: 124-47.

Moss, J. (2012), Aristotle on the Apparent Good. Oxford.

_- (2014), 'Was Aristotle a Humean? A Partisan Guide to the Debate' in R. Polansky (ed.), The Cambridge Companion to Aristotle's Nicomachean Ethics (Cambridge), 221-41.

Pearson, G. (2012), Aristotle on Desire. Cambridge.

Persson, I. (1997), 'Hume - not a “Humean” about Motivation', History of Philosophy

Quarterly 14: 189-206.

Price, A. W. (1995), Mental Conflict. London.

Smith, M. (1987), ‘The Humean Theory of Motivation', Mind 96: 36-61.

Stewart, J. A (1892), Notes on the Nicomachean Ethics. Oxford.

Tuozzo, T. M. (1991), 'Aristotelian Deliberation is Not Of Ends' in J. P. Anton and A. Preus (eds.), Essays in Ancient Greek Philosophy. Vol. 4: Aristotle's Ethics (Albany, NY), 193-212.

_- (1994), 'Conceptualized and Unconceptualized Desire in Aristotle', Journal of the History of Philosophy 32: 525-49.

Wiggins, D. (1980), 'Deliberation and Practical Reason' in A. O. Rorty (ed.), Essays on Aristotle's Ethics (Berkeley), 221-40. 
${ }^{1}$ Price 1995, 111-14; Moss 2012, 161-2; Bobzien 2014, 88; more wavering: Corcilius 2008,

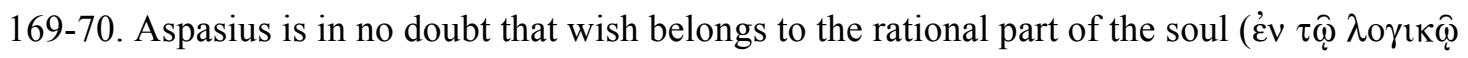

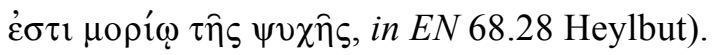

${ }^{2}$ There is disagreement over at least three issues: (i) whether wish is for a single good, (ii) what that good would be, (iii) to what extent a person acting on wish has an articulated conception of the good. For discussion, and further references, see Pearson 2012, 140-4.

${ }^{3}$ Exceptions: Mele 1984a; Tuozzo 1994; Corcilius 2008, 160-207; Pearson 2012, 140-69.

${ }^{4}$ I side with Gotthelf's teleological-naturalistic understanding of the human good in terms of 'the actualization of an irreducible potential for form' (Gotthelf 2012, 45-9).

${ }^{5}$ Contra Moss 2012, 163-74. Cf. also Lorenz 2009.

${ }^{6}$ Irwin 1975; 1978; Cooper 1988; 1996.

${ }^{7}$ For this Humean principle, see Smith 1987, 36-7.

${ }^{8}$ Cf. e.g. Mele 1984a, 147-8; Moss 2012, 155-60.

${ }^{9}$ For some face-value evidence in favour of the claim that deliberation is about ends, see $N E$ $6.5,1140 \mathrm{a} 25-8 ; 6.7,1141 \mathrm{~b} 12-14 ; 6.9,1142 \mathrm{~b} 29-33$.

${ }^{10}$ Cf. Mele 1984a, 146-7; 1984b, 132; Moss 2014, 232.

${ }^{11}$ But see Cooper 1988, 30; Pearson 2012, 182; less unequivocally, Corcilius 2008, 263.

${ }^{12}$ Cf. Aspasius' comment on $N E 3.2,1111 \mathrm{~b} 19-20$, concerning how decision is distinguished from wish: 'For on having deliberated, reason comes to an accord, and makes a choice, wish,

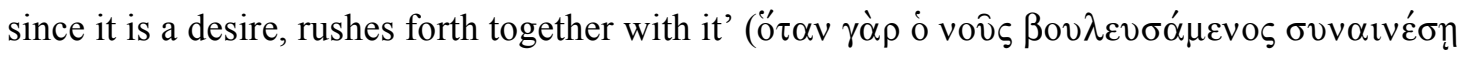

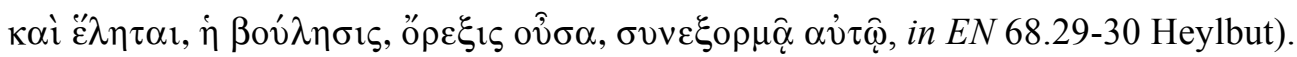

${ }^{13}$ Irwin 1975, 570-1; 1978, 256; Cooper 1975, 21-2, 78-80. See also Wiggins 1980, 224-5.

${ }^{14}$ Arguably, acting courageously may be chosen as a means to becoming courageous. Such actions, however, would not count as fully virtuous. When the virtuous person acts courageously, the action is not a means to becoming courageous, but manifests the permanent disposition to act courageously.

${ }^{15}$ Irwin 1975, 570; Irwin 1978, 257; Cooper 1975, 81-2.

${ }^{16}$ But see Irwin 1978, 261. 
${ }^{17}$ The concern that there is no intelligible account of the desire-producing cognition applies to the further option that wish is produced not by an exercise of reasoning, but through nonpropositional thought (vov̧s), which grasps the ultimate ends intuitively. See Tuozzo 1991, 2024; Majithia 2006, 193-4.

${ }^{18}$ Moss 2012, 155-63, 198-9, 223-7; cf. also Tuozzo 1994, 543.

${ }^{19}$ What the precise position of David Hume might have been is beyond the scope of the inquiry here, but see e.g. Persson 1997.

${ }^{20}$ Moss $(2012,162)$ appeals to Politics $7.15,1334 \mathrm{~b} 22-5$, in which appetite, spirited desire and wish are listed as three inborn desires. Since reason occurs later, this may support the view that wish belongs to the non-rational part of the soul. However, the point might just be that even the as-yet non-rational infant has the propensity for wish.

${ }^{21}$ This does not mean that pleasure in virtuous activity is idle. The function of pleasure, to which I shall turn on another occasion, is to augment the activity by stabilising and intensifying it (NE 10.5, 1175a30-6).

${ }^{22}$ See Corcilius 2008, 181-9. By motivation to pursue I have in mind that for the sake of which the agent acts, or the reasons for action. Corcilius has a very different notion of motivation in mind when he argues that pleasure is motivationally indispensable even for wish-guided actions, since pleasure is required in the causal chain leading to bodily movements.

${ }^{23}$ For a clear statement of the opposite approach, see Corcilius 2008, 161-3. Aristotle's hylomorphism notwithstanding, it should not be forgotten that he has a difficult time explaining how reason is brought into the human organism (GA 2.3, 736 b27-9).

${ }^{24} \delta 1 \alpha \sigma \tau \rho о \varphi \eta ́ v$ at $1227 \mathrm{a} 21-2$ and $1227 \mathrm{a} 30$ is grammatically challenging. I follow Jackson's

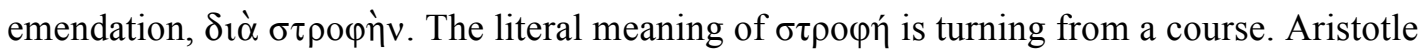
may use the expression as a metaphor for perversion of character.

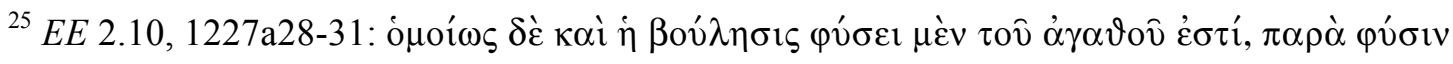

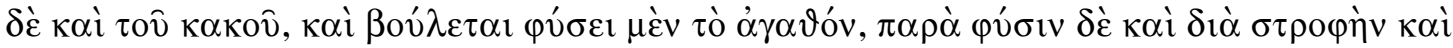

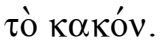

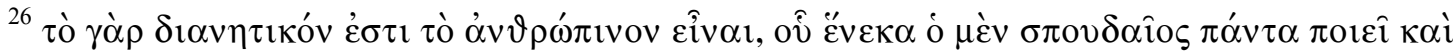

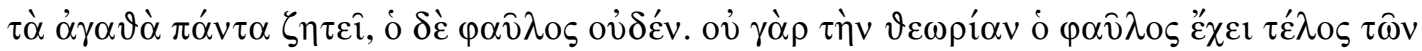

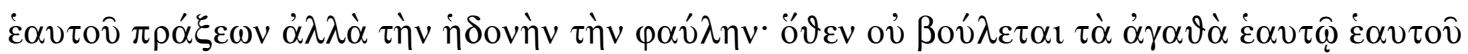

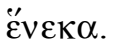


${ }^{27}$ Contra Pearson 2012, 41-7.

${ }^{28}$ The phrase is elliptical, and I take the point to be that what natural appetite is for, or what the object of natural appetite is, is the filling of a lack. Cf. also Plato's distinction between thirst as a desire for restoration of a deficient state of the body in terms of a filling, and thirst as a desire for drink (Philebus 34e9-35c2).

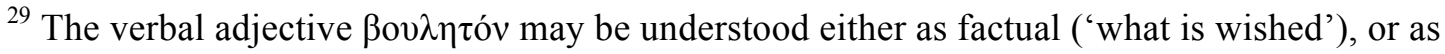
potential ('what can be wished') or as obligatory ('what should be wished'). The factual reading makes best sense of the first horn of the dilemma. The obligatory reading makes particularly bad sense, for the expression 'wishing for what should not be wished' poses no challenge in the first place. The potential reading 'wishing for what cannot be wished for', again, overstates the challenge.

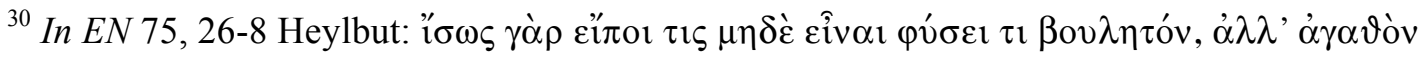

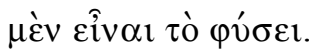

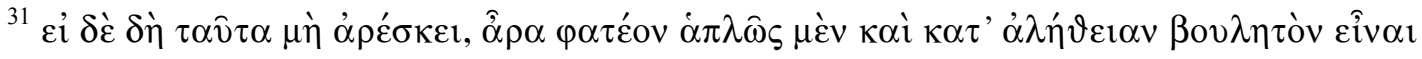

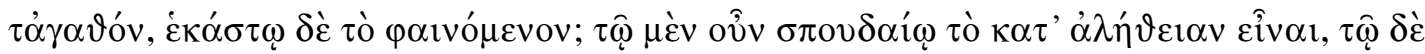

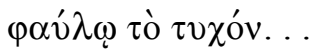

${ }^{32}$ I take the phauloi to refer only to inferior, or bad, rational animals, excluding non-rational animals. For the opposite view, see the anonymous paraphrast, [Heliodor.]. in EN paraphr. 211.35-6 Heylbut; Michael of Ephesus, in EN 538.27-9 Heylbut; Grant 1874, 318; Stewart $1892,407$.

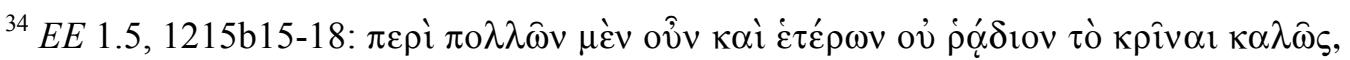

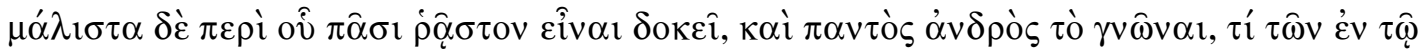

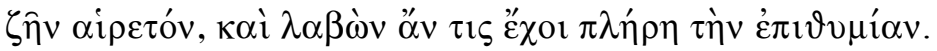

${ }^{35}$ For an account, see Lorenz 2006, 113-37.

${ }^{36}$ Cf. Burnyeat 1980, 73; Mele 1984b, 142-3.

${ }^{37}$ So Mele 1984a, 151; Corcilius 2008, 167-8.

${ }^{38}$ I wish to thank audiences in Stockholm and Uppsala for fruitful discussions, and Jens Johansson, Frans Svensson and Attila Tanyi for comments on drafts of the paper, and the anonymous referee of this journal for instrumental requests for further clarifications. 